\title{
DEVELOPMENT OF A DYNAMIC TRACK MEASURING DEVICE FOR GAUGE AND TWIST TO REDUCE DERAILMENT ACCIDENTS
}

\author{
YOSUKE TSUBOKAWA \& TOMOYUKI ISHIKAWA \\ Railway Technical Research Institute, Japan
}

\begin{abstract}
The track measuring car is very expensive, so static measurement is being carried out not only at regional railway operators but also at major railway operators when it comes to lines in the yard. However, the device for static measurement is lightweight, so it is not possible to obtain dynamic track irregularities due to the wheel load and lateral force during a vehicle running. Therefore, in such a section of the line, a derailment accident may occur when dynamic track irregularity is large due to deterioration of track materials. From the above, with the aim of further reducing derailment accidents, we are developing a low cost measuring device for measuring gauge and twist affecting the driving safety of the vehicle which can be easily mounted on a motor car. This device measures the relative displacement between the device and the rail by the two-dimensional laser sensor and can display the rail profile of the measurement position during data processing. Therefore, when large measurement values are seen, it is possible to grasp whether there is a significant track irregularity at the site or an error at the time of measurement. In addition, we developed a mounting method using the traction coupler of track motor car or bolts for installing the guard iron of passenger vehicles, and carried out the running test at a speed of up to $40 \mathrm{~km} / \mathrm{h}$ to confirm the measuring performance. As a result of calculating the reproducibility (standard deviation of the difference between the two measured values) using measurement data of various speeds, it is confirmed that this device has measurement accuracy equivalent to that of the existing track measuring car. In this paper, we report the outline of the measuring device and the results of running tests conducted to confirm its performance.
\end{abstract}

Keywords: dynamic track measuring device, gauge, twist, reproducibility, the wide gange derailment, the flange climb derailment.

\section{INTRODUCTION}

Types of derailment accidents caused by track condition include the wide gauge derailment due to gauge expanding [1] and the flange climb derailment due to large twist in the curve section [2]-[4]. These derailment accidents in Japan are caused by the dynamically increasing track irregularities due to the wheel load and the lateral force acting on the track when the vehicle running in the section where the track materials are deteriorated. Therefore, it is necessary to measure dynamic track irregularity during running of the vehicle and maintain track based on the result to prevent a derailment accident related to such a track condition. On the other hand, the track measuring car like Dr. Yellow [5] used for dynamic measurement of track irregularity is very expensive, so it is difficult for regional railway operators with poor management status to introduce it. Although they measure track irregularity using a trolley-type measuring device or the like, the device that measures a static track irregularity is lightweight and can't obtain dynamic track irregularity during running of the vehicle.

Therefore, in order to further reduce the derailment accident causing the track condition, we developed a measuring device that can be installed in a vehicle and can measure dynamic irregularity of gauge and twist which are greatly affecting the deterioration of the running safety of the vehicle. In this paper, we outline the developed measuring device and the result of running test. 


\section{OUTLINE OF A TRACK MEASURING DEVICE FOR GAUGE AND TWIST}

Outline of derailment accident caused by track condition is shown in Fig. 1. As shown in Fig. 1(a), the wide gauge derailment is a phenomenon in which wheels fall to the inside of the gauge, and it is often caused by a decrease in rail fastening force due to wooden sleeper corrosion or the like. As shown in Fig. 1(b), the flange climb derailment is a phenomenon in which wheels ride on rails and derail. One of the factors is that as the vehicle runs on the track with a loose sleeper due to deterioration of ballast, track irregularity of twist increases and wheel load is decreases. In this chapter, the outline of the developed device which can measure track irregularity of gauge and twist will be explained.

\subsection{Composition of a track measuring device for gauge and twist}

The composition of the developed device is shown in Fig. 2. This device consists of a sensor unit, a pulse converter, a controller and PC for measuring. A sensor unit incorporates a twodimensional laser sensor composed of a laser and a camera and an angle sensor. The size of a sensor unit is $860 \mathrm{~mm}$ in width, $160 \mathrm{~mm}$ in height, $230 \mathrm{~mm}$ in depth, and weight is approximately $10 \mathrm{~kg}$, which is smaller and lighter than a sensor unit of a typical track measuring car.

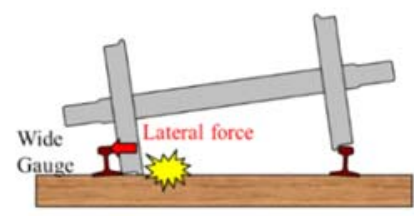

OCorrosion of wood sleeper Fastening device defect

$\Rightarrow$ Lateral force acts on a track

$\Rightarrow$ Wide gauge(Increase rail tilting)

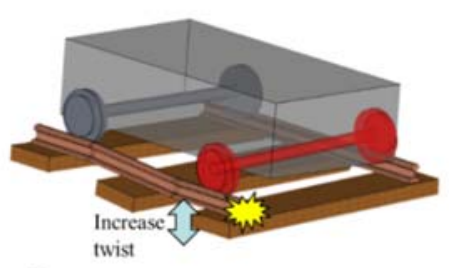

OBallast deterioration

Loose sleeper

$\Rightarrow$ Increase twist due to vehicle travel

$\Rightarrow$ Decrease of wheel load

(Increase in derailment quotient)

$\Rightarrow$ The wheels ride on the rail

Figure 1: Derailment accident caused by track condition. (a) The wide gauge derailment; (b)The flange climb derailment.

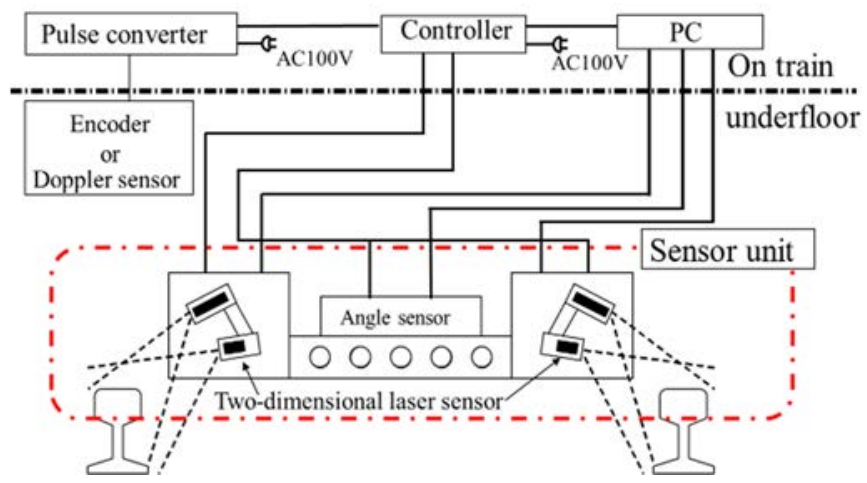

Figure 2: Composition of the developed measuring device. 
The pulse converter receives the pulse signal of the encoder and calculates speed and measurement distance. The controller supplies power to each sensor and controls the sensor.

\subsection{Outline of the developed measuring device}

\subsubsection{Measurement method of gauge and twist}

Our device measures the relative displacement from both ends of the device to the top surface and the side surface of the rail with a two-dimensional laser sensor and measures the inclination of the device with respect to the upper surface of the rail with an angle sensor.

Irregularity of gauge is calculated from the relative displacement to the side of the rail. The measurement position on the side of the rail can be selected with a distance of $14 \mathrm{~mm}$ or $16 \mathrm{~mm}$ from the top of the rail head so that it can correspond to the definition of each railway operator.

Irregularity of twist is calculated from the cross level measured with the device. Cross level is calculated by (1) from the relative displacement to the rail head top surface and the inclination of the device with respect to the rail top surface

$$
S=1067 \tan \left(\tan ^{-1}\left(\frac{z_{r}-z_{l}}{1067}\right)-\varphi\right)
$$

where $\mathrm{S}$ is cross level, $\mathrm{z}_{\mathrm{l}}$ and $\mathrm{z}_{\mathrm{r}}$ are the relative displacement to the top of the rail of the left and right rails, and $\varphi$ is the roll angle. The interval of cross level used for calculating twist can be selected from $2.0 \mathrm{~m}, 2.5 \mathrm{~m}$, and $5.0 \mathrm{~m}$ so as to correspond to the definition of each railway operator.

\subsubsection{Output of measurement result}

Fig. 3 shows the output screen of the PC as the measurement result of our device. In the output screen, the measurement positions of track irregularity, measured values of gauge, cross level and twist are shown in the table.

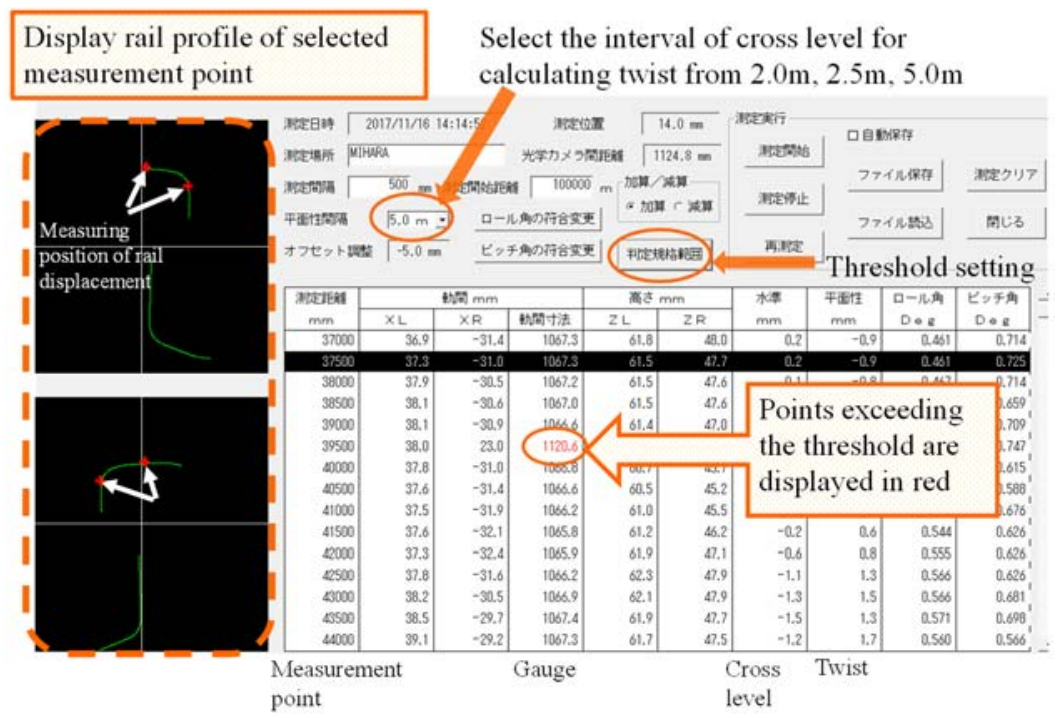

Figure 3: Output screen of the PC as the measurement result of the device. 
For each measured value, it is displayed in red if it exceeds a preset threshold (for example reference value). Also, when we select the measurement position we want to check with the mouse cursor, we can know the rail profile of that position and the measurement position of the rail displacement. When we check abnormal measured values, we can grasp whether there is a significant track irregularity at the site or an error at the time of measurement.

\subsection{Performance evaluation method of measuring device of track irregularity in Japan}

The track measuring device requires high measurement accuracy. We will show the verification method of the measurement accuracy of the track measuring device (including the case where the track measuring device is mounted) commonly used in Japan. We evaluate the accuracy of a measuring device in the following order (1) to (5).

1. Repeat the same section repeatedly with a measuring device. At this time, the measuring section is set to include a straight line and a curve (preferably including the minimum curve radius in the route).

2. In the measurement section, we set the evaluation section to perform accuracy verification. When setting up the evaluation section, we take care not to include the part where the track dynamically deforms due to the force acting on the track while the vehicle is running. In addition, set a section of at least $1 \mathrm{~km}$ or more for both straight lines and curved lines (curves are not necessarily one curve).

3. For the longitudinal level and the alignment, in consideration of the characteristics of the transfer function of the track measuring device, band-pass filter processing with a wavelength of $6 \mathrm{~m}$ to $80 \mathrm{~m}$ is performed. For cross level, drift components are eliminated by high pass filter processing or the like. For gauge and twist, do not perform filter processing and evaluate with measured values.

4. For the two measured data, compare the position of the waveform and subtract it. In this case, we will perform location verification using cross-correlation method as needed.

5. For the data obtained by subtraction, divide the evaluation section into fixed intervals (generally 200m), calculate the standard deviation.

Table 1 shows the repeatability accuracy required for track inspection car used in Japan. We define this standard deviation as repeatability and check whether the values in Table 1 are satisfied. The method of evaluating the measurement performance of the measuring device of track irregularity is also presented in the EN standard [6], [7]. From the above, we also evaluate the measurement performance of our device by the same method.

Table 1: Required repeatability accuracy for track measuring device.

\begin{tabular}{|l|c|c|}
\hline Kind of track irregularity & Shinkansen & Conventional line \\
\hline Longitudinal level & $0.3 \mathrm{~mm}$ & $0.5 \mathrm{~mm}$ \\
\hline Alignment & $0.3 \mathrm{~mm}$ & $0.5 \mathrm{~mm}$ \\
\hline Gauge & $0.3 \mathrm{~mm}$ & $0.5 \mathrm{~mm}$ \\
\hline Cross level(cant) & $0.5 \mathrm{~mm}$ & $1.0 \mathrm{~mm}$ \\
\hline Twist & $0.5 \mathrm{~mm}$ & $1.0 \mathrm{~mm}$ \\
\hline
\end{tabular}




\section{CONSIDERATION ON A METHOD OF INSTALLING A DEVICE IN A VEHICLE}

We examined methods to install our device in the vehicle to measure the dynamic track irregularity with our device. Here, we will describe the method of installing our device in a motor car, and a bogie for a commercial vehicle.

We decided to install our device using a traction device, which is considered to be a structure common to many motor cars. Fig. 4(a) shows the installation position of the sensor unit in the motor car. This part used for installing the sensor unit is about $22 \mathrm{~kg}$. In the case of this method, the distance from the wheel position to the measuring position by laser is $1.15 \mathrm{~m}$. The attachment and detachment of the sensor unit can be carried out by one person, and the time required takes about 30 minutes.

Next, we decided to use guard iron mounting parts in order to install our device in commercial vehicles without making significant improvement of a bogie. Fig. 4(b) shows the installation position of the sensor unit on bogie for a commercial vehicle. In this installation method, the distance from the wheel position to the measuring position by laser is $0.95 \mathrm{~m}$. That is, it can be measured at a position close to the wheel as compared with installing on the motor car. The work of attaching the sensor unit was about 1.5 hours.

\section{VERIFICATION OF MEASUREMENT ACCURACY BY RUNNING TEST}

\subsection{The running test with motor car}

We verified the measuring performance of gauge by running test of the motor car with a curve of about $400 \mathrm{~m}$ in radius and about $30 \mathrm{~mm}$ in cant. The landscape of running test is shown in Fig. 5. In a section of the running test, we removed the rail fastening system for up to four sleeper, measured the displacement of the rail in the lateral direction when passing through the motor car, and compared it with the gauge measured by our device.

Fig. 6 shows the measurement result of irregularity of gauge. The measurement result of our device was approximately overlapped except for the section where the rail fastening

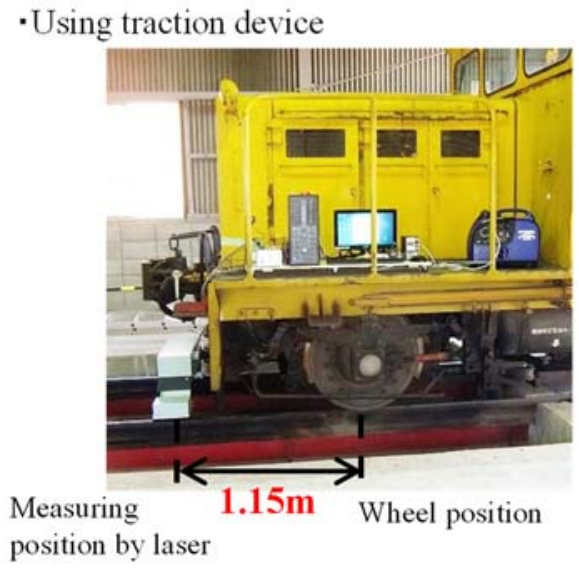

(a)

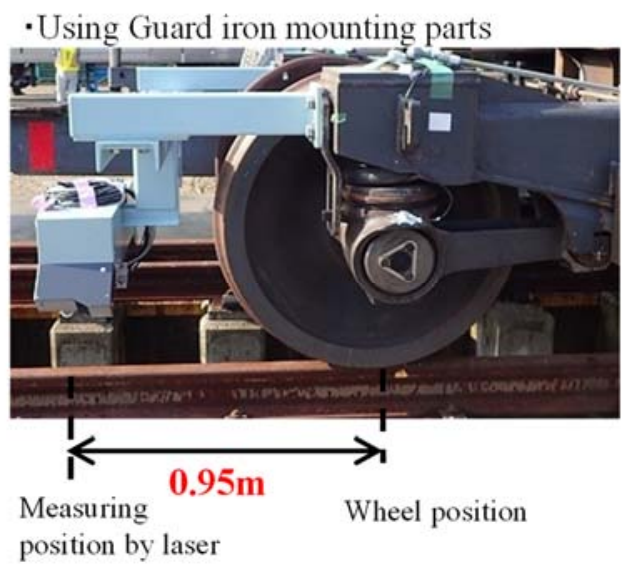

(b)

Figure 4: Output screen of the PC as the measurement result of the device. (a) Installation method on motor car; (b) Installation method on bogie for a commercial vehicle. 
system was removed, and the repeatability of the gauge was $0.20 \mathrm{~mm}$. From the above, it was confirmed that gauge can be measured with high accuracy like the existing measuring device. Next, the measurement result of irregularity of gauge in the rail fastening system removal section is shown in Fig. 7. The irregularity of gauge measured in the section where the foursleeper rail fastening systems were removed was $0.49 \mathrm{~mm}$ larger than the state of all rail fastening systems.

Fig. 8 shows the result of measuring the displacement of the rail in the lateral direction called dynamic irregularity of gauge when passing through the motor car. As described above, the sensor unit of our device is mounted at a distance of $1.15 \mathrm{~m}$ from the wheel of the motor car. When the motor car runs at a speed of $10 \mathrm{~km} / \mathrm{h}$, the sensor unit passes the position of the wheel after 0.43 seconds. Therefore, since it is considered that the displacement of the rail in the left-right direction becomes the maximum when passing through the wheel, the expansion amount of the gauge can be obtained from the displacement in the left-right direction after 0.43 seconds. As a result, the expansion amount of the gauge was $0.77 \mathrm{~mm}$ at test condition that the rail fastening device was removed and $0.15 \mathrm{~mm}$ at all the conditions of the rail fastening device, and the difference was $0.62 \mathrm{~mm}$.

This result is about the same as the increment of gauge measured by our device. From this, it can be found that our device can measure dynamic irregularity of gauge. On the other hand, we found that it is desirable to mount our device closer to the wheel to measure the dynamic irregularity of gauge when passing through the wheel. That is, regarding the mounting position of the device, it is necessary to consider the structure of the vehicle in the future.

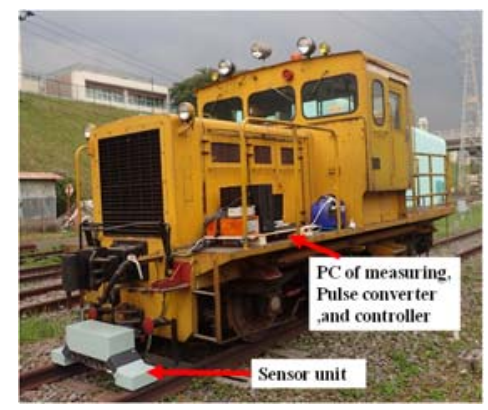

Figure 5: Motor car running test.

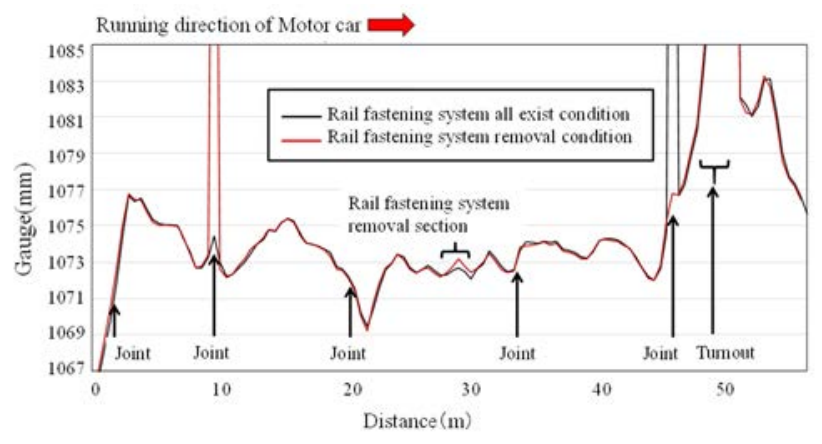

Figure 6: Measurement result of irregularity of gauge. 


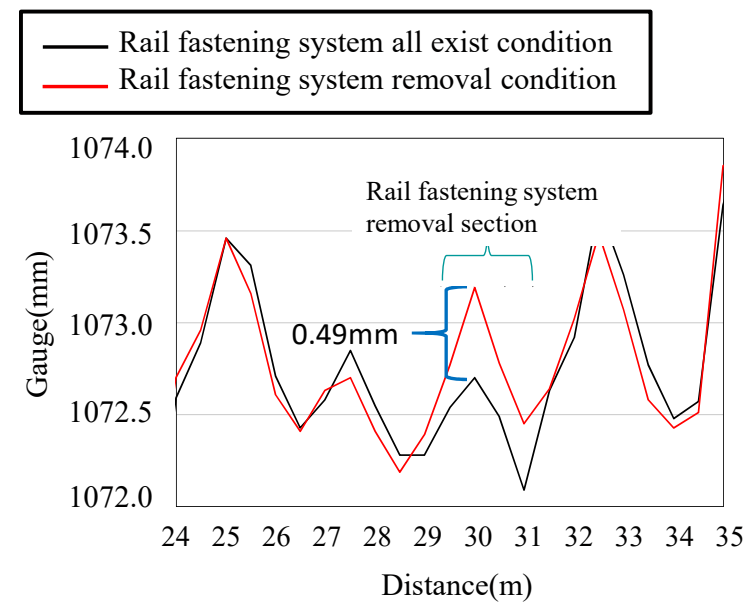

Figure 7: Measurement result of gauge at rail fastening system removal section.
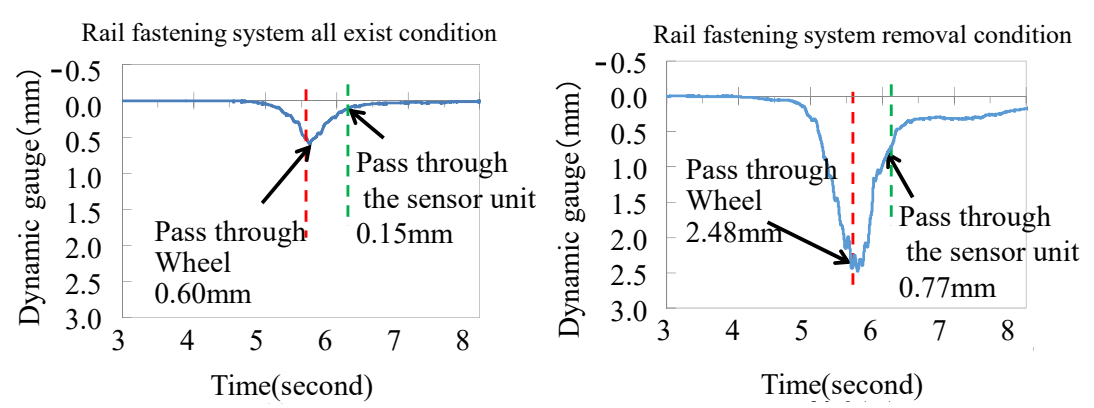

Figure 8: Result of dynamic gauge (the displacement of the rail in the lateral direction).

\subsection{The running test with commercial vehicle}

We have verified the measuring performance of gauge and twist by running test with commercial vehicles on a line with minimum curve radius of $120 \mathrm{~m}$, maximum can't of $107 \mathrm{~mm}$ (gauge $=1067 \mathrm{~mm})$, maximum gradient of $50 \%$. The running speed of the vehicle was 10 to $40 \mathrm{~km} / \mathrm{h}$. The landscape of running test is shown in Fig. 9.

Fig. 10 shows the measurement results of gauge, cross level and twist with speed of $10 \mathrm{~km} / \mathrm{h}$ and $40 \mathrm{~km} / \mathrm{h}$. In this figure, the measurement data of both are almost overlapping except for the level crossing and the turnout where the rail could not be detected by our device. This result is the same even at speeds of $20 \mathrm{~km} / \mathrm{h}$ and $30 \mathrm{~km} / \mathrm{h}$, and it can be found that our device can measure irregularity of gauge and cross level even if the running speed is different.

We divided the measurement data every $200 \mathrm{~m}$ and calculated the repeatability. The results are shown in Table 2. As a result, except for the section including level crossing and turnout, the repeatability of gauge was $0.3 \mathrm{~mm}$ or less, the repeatability of $5 \mathrm{~m}$ twist was mostly $1.0 \mathrm{~mm}$ or less. Therefore, we found that the track irregularity can be measured with the same accuracy as the existing track measuring device. 
Next, in the section where the radius of $120 \mathrm{~m}$ and the steep gradient of $50 \%$ and vertical curve coexist, the measured values of our device and the measured values of the trolley type measuring device were compared. Fig. 11 shows the results of data. As a result, even under such severe linear conditions, the cross level of the device does not drift and is similar to the measurement value by trolley type measuring device. Therefore, we confirmed that irregularity of cross level and twist can be measured with sufficient accuracy even in the section where the curve and the gradient or the vertical curve coexist.

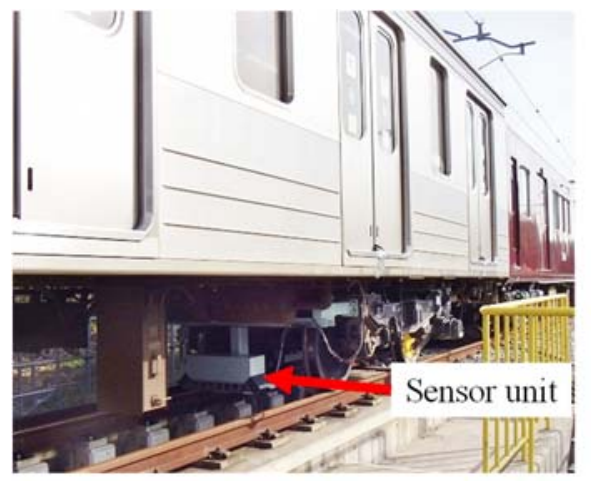

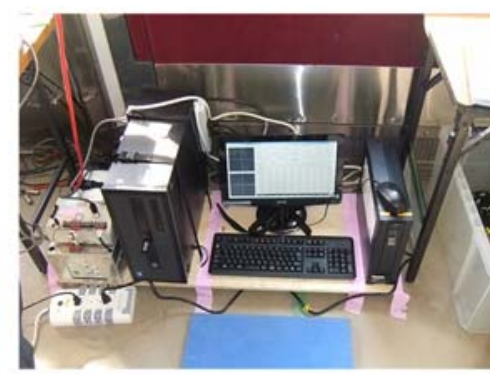

Mounted on the vehicle floor

Figure 9: Commercial vehicle running test.
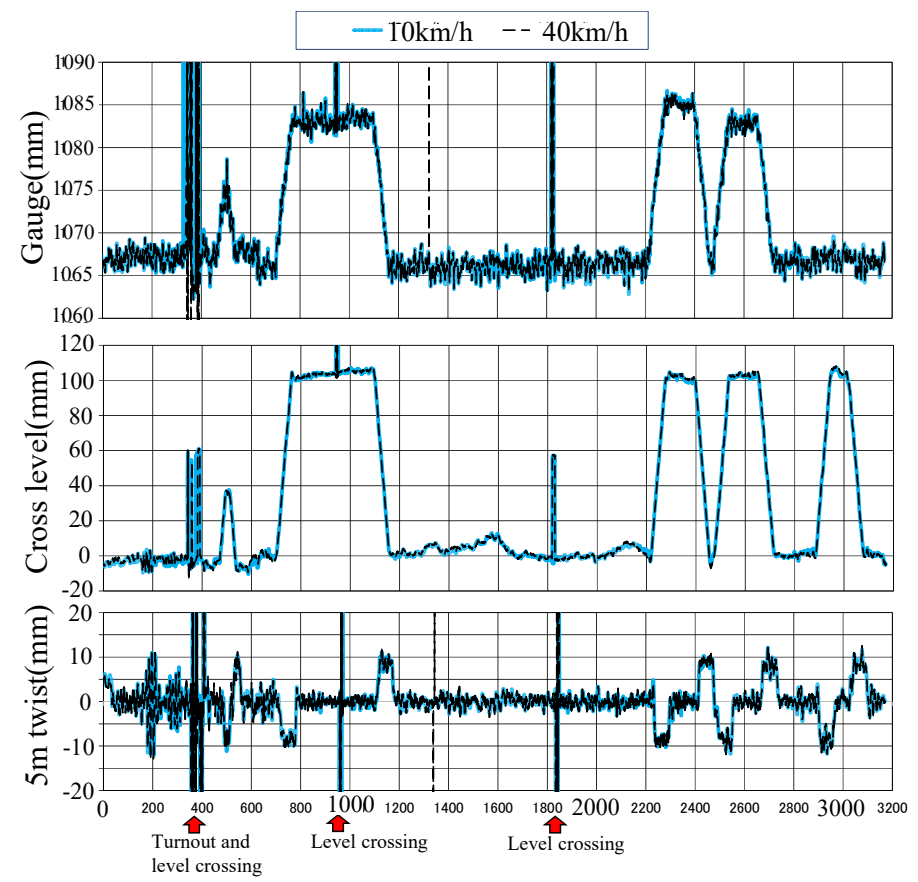

Distance $(\mathrm{m})$

Figure 10: Result of dynamic gauge (the displacement of the rail in the lateral direction). 
Table 2: Repeatability of gauge and twist. (a) Gauge; (b) Twist.

\begin{tabular}{|r|r|r|r|r|r|r|r|}
\hline \multicolumn{2}{|c|}{ Distance } & \multicolumn{7}{|c|}{ Speed of comparison data(km/h) } \\
\hline から & まで & $10-20$ & $10-30$ & $10-40$ & $20-30$ & $20-40$ & $30-40$ \\
\hline $0 \mathrm{~m}$ & $200 \mathrm{~m}$ & 0.12 & 1.51 & 0.23 & 1.50 & 0.13 & 1.50 \\
\hline $200 \mathrm{~m}$ & $400 \mathrm{~m}$ & 9.82 & 5.87 & 10.92 & 11.01 & 9.78 & 10.79 \\
\hline $400 \mathrm{~m}$ & $600 \mathrm{~m}$ & 0.16 & 0.13 & 0.27 & 0.18 & 0.17 & 0.29 \\
\hline $600 \mathrm{~m}$ & $800 \mathrm{~m}$ & 0.12 & 0.08 & 0.21 & 0.13 & 0.12 & 0.21 \\
\hline $800 \mathrm{~m}$ & $1 \mathrm{k} 000 \mathrm{~m}$ & 5.09 & 4.01 & 5.38 & 4.94 & 3.64 & 4.24 \\
\hline $1 \mathrm{k} 000 \mathrm{~m}$ & $1 \mathrm{k} 200 \mathrm{~m}$ & 0.13 & 0.09 & 0.14 & 0.11 & 0.08 & 0.13 \\
\hline $1 \mathrm{k} 200 \mathrm{~m}$ & $1 \mathrm{k} 400 \mathrm{~m}$ & 0.12 & 0.06 & 2.51 & 0.14 & 2.51 & 2.51 \\
\hline $1 \mathrm{k} 400 \mathrm{~m}$ & $1 \mathrm{k} 600 \mathrm{~m}$ & 0.10 & 0.07 & 0.11 & 0.14 & 0.06 & 0.14 \\
\hline $1 \mathrm{k} 600 \mathrm{~m}$ & $1 \mathrm{k} 800 \mathrm{~m}$ & 0.10 & 0.07 & 0.10 & 0.14 & 0.06 & 0.13 \\
\hline $1 \mathrm{k} 800 \mathrm{~m}$ & $2 \mathrm{k} 000 \mathrm{~m}$ & 4.88 & 2.88 & 5.45 & 4.94 & 3.58 & 5.47 \\
\hline $2 \mathrm{k} 000 \mathrm{~m}$ & $2 \mathrm{k} 200 \mathrm{~m}$ & 0.10 & 0.17 & 0.09 & 0.22 & 0.07 & 0.20 \\
\hline $2 \mathrm{k} 200 \mathrm{~m}$ & $2 \mathrm{k} 400 \mathrm{~m}$ & 0.15 & 0.13 & 0.17 & 0.18 & 0.18 & 0.16 \\
\hline $2 \mathrm{k} 400 \mathrm{~m}$ & $2 \mathrm{k} 600 \mathrm{~m}$ & 0.19 & 0.10 & 0.13 & 0.18 & 0.16 & 0.11 \\
\hline $2 \mathrm{k} 600 \mathrm{~m}$ & $2 \mathrm{k} 800 \mathrm{~m}$ & 0.17 & 0.09 & 0.10 & 0.17 & 0.17 & 0.11 \\
\hline $2 \mathrm{k} 800 \mathrm{~m}$ & $3 \mathrm{k} 000 \mathrm{~m}$ & 0.15 & 0.07 & 0.08 & 0.15 & 0.15 & 0.08 \\
\hline $3 \mathrm{k} 000 \mathrm{~m}$ & $3 \mathrm{k} 200 \mathrm{~m}$ & 0.14 & 0.05 & 0.06 & 0.13 & 0.13 & 0.06 \\
\hline average & 0.13 & 0.09 & 0.14 & 0.16 & 0.12 & 0.15 \\
\hline
\end{tabular}

\begin{tabular}{|c|c|c|c|c|c|c|}
\hline \multicolumn{6}{|c|}{ Speed of comparison data $(\mathrm{km} / \mathrm{h})$} & \multirow[t]{2}{*}{ Error } \\
\hline $10-20$ & $10-30$ & $10-40$ & $20-30$ & $20-40$ & $30-40$ & \\
\hline 0.74 & 1.73 & 0.87 & 1.78 & 0.98 & 1.85 & Error $(30 \mathrm{~km} / \mathrm{h})$ \\
\hline 14.68 & 13.20 & 18.59 & 18.18 & 16.47 & 18.97 & Turnout, Level crossing \\
\hline 0.92 & 0.95 & 1.08 & 1.08 & 0.99 & 1.13 & \\
\hline 0.67 & 0.52 & 0.75 & 0.69 & 0.71 & 0.66 & \\
\hline 13.15 & 9.89 & 15.31 & 14.01 & 11.38 & 14.69 & Level crossing \\
\hline 0.49 & 0.54 & 0.55 & 0.47 & 0.50 & 0.50 & \\
\hline 0.42 & 0.52 & 1.62 & 0.47 & 1.59 & 1.62 & Error $(40 \mathrm{~km} / \mathrm{h})$ \\
\hline 0.47 & 0.43 & 0.50 & 0.42 & 0.49 & 0.47 & \\
\hline 0.42 & 0.40 & 0.45 & 0.39 & 0.45 & 0.39 & \\
\hline 9.62 & 6.16 & 10.51 & 9.64 & 7.46 & 10.56 & Level crossing \\
\hline 0.35 & 0.63 & 0.52 & 0.63 & 0.48 & 0.68 & \\
\hline 0.79 & 0.79 & 0.87 & 0.77 & 0.74 & 0.78 & \\
\hline 0.58 & 0.72 & 0.69 & 0.71 & 0.63 & 0.65 & \\
\hline 0.59 & 0.59 & 0.53 & 0.68 & 0.64 & 0.61 & \\
\hline 0.41 & 0.46 & 0.54 & 0.50 & 0.59 & 0.53 & \\
\hline 0.49 & 0.47 & 0.48 & 0.49 & 0.51 & 0.48 & \\
\hline 0.56 & 0.59 & 0.65 & 0.61 & 0.64 & 0.63 & \\
\hline
\end{tabular}
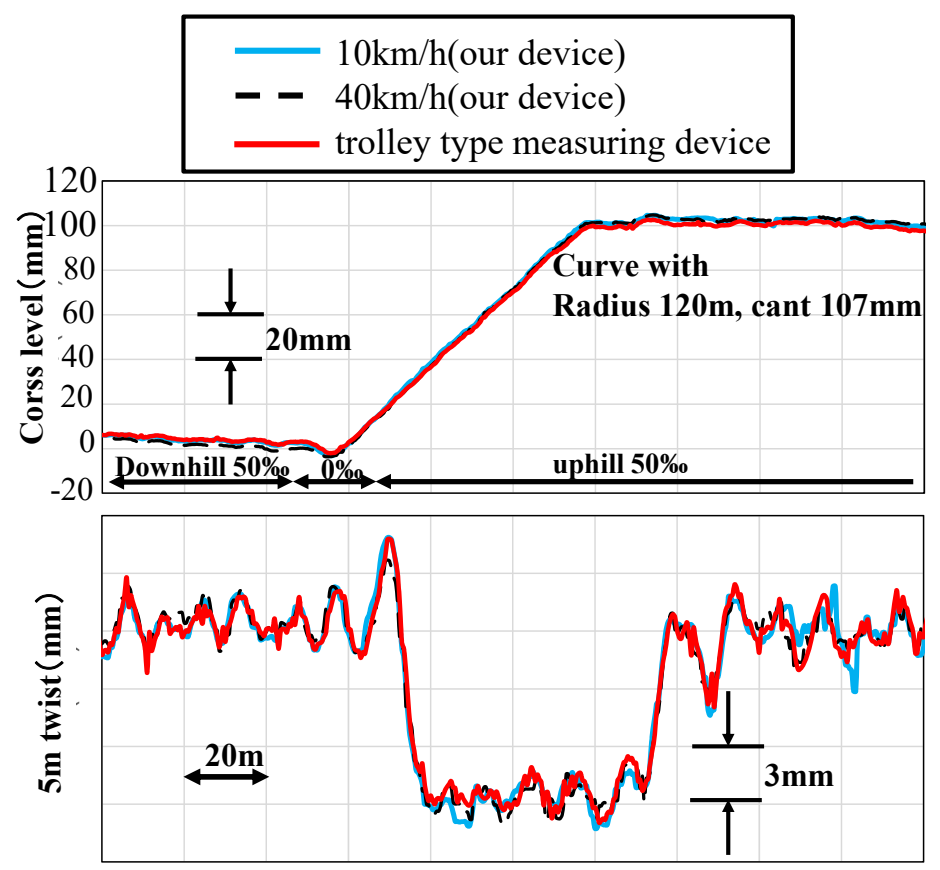

Figure 11: Measurement results of coexistence section of curve, gradient, and vertical curve.

\section{CONCLUSION}

We developed a device that can measure dynamic irregularity of gauge and twist which have a large influence on the running safety of the vehicle with the aim of further reducing the derailment accident causing the track condition. As a result of calculating the repeatability of the measurement data by carrying the running test with our device mounted on a vehicle, repeatability of gauge was $0.3 \mathrm{~mm}$ or less and repeatability of $5 \mathrm{~m}$ twist was $1.0 \mathrm{~mm}$ or less. From the above, it was confirmed that the measurement accuracy of our device is equivalent to that of existing track measuring device. 


\section{REFERENCES}

[1] Japan Transport Safety Board, Between Nishihata station and Kazusa Nakano station, Single Track, Isumi Line (Railway accident investigation report), 2015.

[2] Hiroaki, I. et al., Safety assessment for flange climb derailment of trains running at low speeds on sharp curves. Quarterly Report of RTRI, 47(2), pp. 65-71, 2006.

[3] Hiroaki, I., Safety assessment of railway vehicles and measures against derailment. International Forum on Railway Engineering - 2010 in Taiwan, 2010.

[4] Wu, H. \& Wilson, N., Flange climb derailments: causes and prevention. International Railway Journal, 52(3), 2012.

[5] Naganuma, Y., Tanaka, M. \& Ichikawa, K., High-speed track inspection car in the new dr. yellow. Proceedings of the World Congress on Railway Research (WCRR 2001), 2001.

[6] En13848-1:2003+A1:2008 railway applications - Track - Part 1: Characterisation of track geometry, 2008.

[7] Tsubokawa, Y. \& Tanaka, H., Accuracy validation method and verification results of track measuring device with the inertial mid chord offset method. Railway Engineering$2017,2017$. 